\title{
Las terapias complementarias en una unidad de hemodiálisis
}

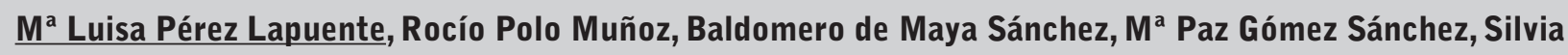 \\ Meseguer Hernández, Esperanza Melero Rubio
}

\section{Unidad de Hemodiálisis. Hospital Universitario Virgen de la Arrixaca. Murcia}

\section{Introducción:}

Los profesionales sanitarios dan importancia a las terapias complementarias (TC) y hospitales de todo el mundo la usan ${ }^{(1)}$. Incluir terapias energéticas como prácticas enfermeras ayuda a lograr una mejor armonía del individuo(2) pues el desequilibrio del campo energético produce problemas de salud ${ }^{(3)}$ y Reiki regula el organismo en situaciones de desequilibrio ${ }^{(4)}$. Ciertas TC dan resultado descartando un efecto placebo ${ }^{(5)}$, Reiki mejora la ansiedad y los valores analíticos ${ }^{(6)}$. Regulando las TC se incorporarían a la atención convencional(7).

\section{Objetivos:}

Valorar el grado de conocimiento del personal de HD sobre las TC y concretamente de Reiki: indicaciones, efecto placebo, esoterismo y clandestinidad.

\section{Metodología:}

Estudio descriptivo transversal en febrero de 2012. Se elaboró un cuestionario y se pasó a 50 profesionales.

\section{Resultados:}

El $18 \%(n=9)$ eran hombres y el $82 \%(n=41)$ mujeres. La media de edad fue de 46 años con desviación típica de $\pm 10,17$. En relación a la profesión: $44 \%$ DIplomado Universitario en Enfermería (DUE), $28 \%$ Auxiliares de enfermería (AAEE), 16\% médicos, $6 \%$ residentes, $4 \%$ limpiadoras, $2 \%$ celadores. Destacar que el $100 \%$ de la muestra conocía la existencia de
TC. El $88 \%$ las usaba. El $12 \%$ afirmó no usar ninguna y un $93 \%$ recurriría a ellas como último recurso. Las TC más usadas fueron: Homeopatía 56\%, Masajes 44\%, Hidroterapia 36\%, Yoga 24\%, Reiki 22\%, para aliviar el dolor articular: $42 \%$, dolor de espalda $40 \%$, insomnio $28 \%$, ansiedad $26 \%$ y cefalea $16 \%$. El $54 \%$ de la muestra conocía el Reiki y el $38 \%$ lo experimentó: $72,7 \%$ dolor de espalda; $54,5 \%$ ansiedad y dolor articular y $36,4 \%$ insomnio. Un $46 \%$ afirma que Reiki no tiene un efecto placebo. Un $42 \%$ asegura que se practica clandestinamente aunque no se considere esotérico por la mayoría (72\%).

\section{Discusión:}

El éxito de las TC se debe al tratamiento personalizado y a tener en cuenta el estado subjetivo de la persona $^{(8)}$. En 2011 según el Observatorio de Terapias Naturales, en España 95,4\% conoce alguna. De los entrevistados el $100 \%$ las conoce. Las cuatro TC más usadas en España son Yoga, Quiromasaje, Homeopatía y Acupuntura. Las tres primeras son las más utilizadas por el personal de la unidad de HD. El 23,6\% de los españoles usó TC y el personal de HD el $88 \%$, según nuestro estudio. El insomnio prevalece en los sanitarios debido a los turnos, por ello el $36,4 \%$ usa Reiki para el descanso y el estado de ánimo. Reiki ayudaría a las enfermeras a sanarse a sí mismas y a otros ${ }^{(9)}$ pues existe interacción entre nuestras emociones, pensamientos y actos con el organismo ${ }^{(10)}$. En el estudio sólo el $22 \%$ ha probado Reiki. Deberíamos realizar ensayos controlados aleatorios para comprobar la eficacia del Reiki ${ }^{(11)}$, así establecer su rigor científico y estandarizar intervenciones ${ }^{(12)}$. 


\section{Conclusiones:}

Toda la muestra conoce las TC y la mayoría las ha usado. Los facultativos recurren menos a ellas a no ser que fuese imprescindible. Hay un gran desconocimiento sobre los beneficios del Reiki. Haciendo charlas informativas en la unidad despertaríamos el interés por las TC favoreciendo su uso.

\section{Referencias Bibliográficas}

1. Pressman AH, Buff S. Medicina alternativa. México: Pearson Educación; 2001.

2. Aparicio MR, González AJ. Cuidadoras y terapias alternativas: un abordaje integral. Paraninfo Digital [Revista en Internet]. 2010 [acceso 6 de junio de 2012]; 10. Disponible en: http://www.indez-f. com/para/n10/pl08.php.

3. O'Mathuna DP, Ashford RL. Toque terapéutico para la curación de las heridas agudas (Revisión Cochrane traducida). En: La Biblioteca Cochrane Plus, 2008 Número 4. Oxford: Update Software Ltd. Disponible en: http://www.update-software.com (Traducida de The Cochrane Library, 2008 Issue 3. Chichester, UK: John Wiley \& Sons, Ltd.).

4. Díaz Rodríguez L, García La Fuente F, Tomás Rojas I, Rodríguez Alvarez E, García Royo C, Arroyo Morales $\mathrm{M}$, et al. El Reiki como terapia alternativa en los cuidados de la salud. Rev Paraninfo Digital 2009;7.

5. Brofman, M. Todo se puede curar. Málaga: Sirio; 2004.
6. Beem L, Morse M. Benefits of Reiki Therapy for a Severely Neutropenic Patient with Associated Influences on a True Random Number Generator. J Altern Complemen Med. 2011 diciembre; 17(12):1181-1190. doi:10.1089/ acm.2010.0238.

7. Lorenc, A., Peace, B., Vaghela, C., y Robinson, N. The integration of healing into conventional cancer care in the UK. Complementary Therapies In Clinical Practice. 2010; 16 (4), 222-228.

8. Stiftung W, Federspiel K, Herbst V. Guía de las terapias alternativas: principios, eficacia y riesgos. Madrid: OCU; 2001.

9. Natalie GW. Reconnecting to nursing through Reiki. Creative Nursing. 2010; 16 (4): 171-176.

10. Peters $D$, Woodham $A$. Medicina integrada. BarceIona: Ediciones B; 2001.

11. Anderson J, Gill A. Effects of healing touch in clinical practise: A systematic review of randomized clinical trials. J Holist Nurs. [Revista en Internet]. 2011 septiembre. [acceso 24 de marzo de 2012]; 29(3):221-228. Disponible en: http://www.ncbi. nlm.nih.gov/pubmed/21228402.

12. VanderVaart S, Gijsen VM, de Wildt SN, Koren G. A systematic review of the therapeutic effects of Reiki. Journal of Alternative \& Complementary Medicine. 2009; 15(11): 1157-1169. doi:10.1089/ acm.2009.0036. 